\title{
Der Gummidruck
}

\section{Praktische Anleitung}

für

Freunde künstlerischer Photographie

von

\section{Prof. Friedrich Behrens \\ Oberlehrer \\ am Realgymnasium zu Lankwitz b. Berlin}

Mit einer Zweifarbendruckbeilage und mehreren Abbildungen

Dritte verbesserte Auflage

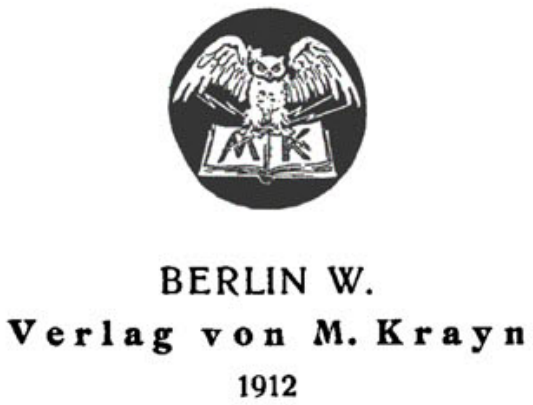

Prels 1.50 Mark 


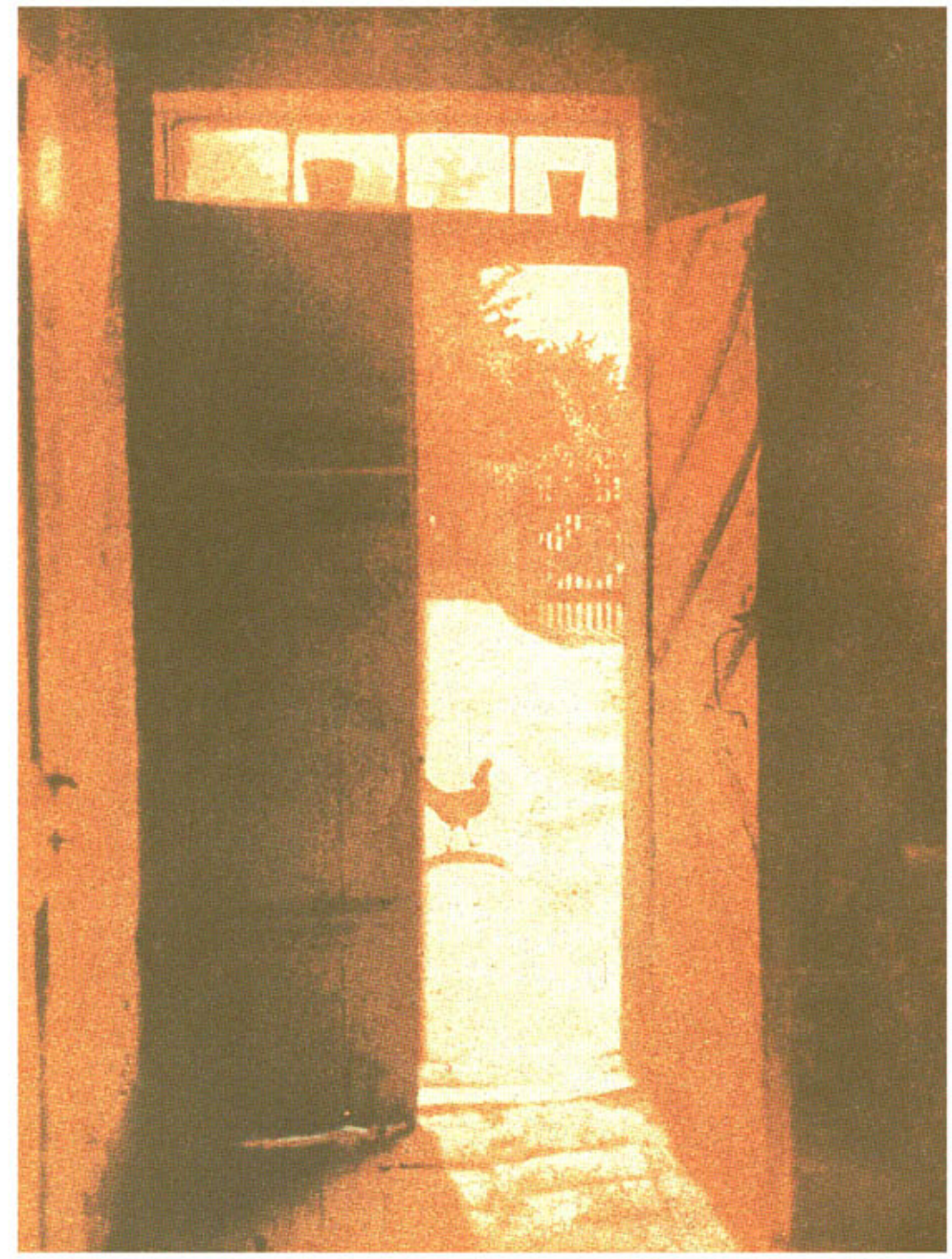




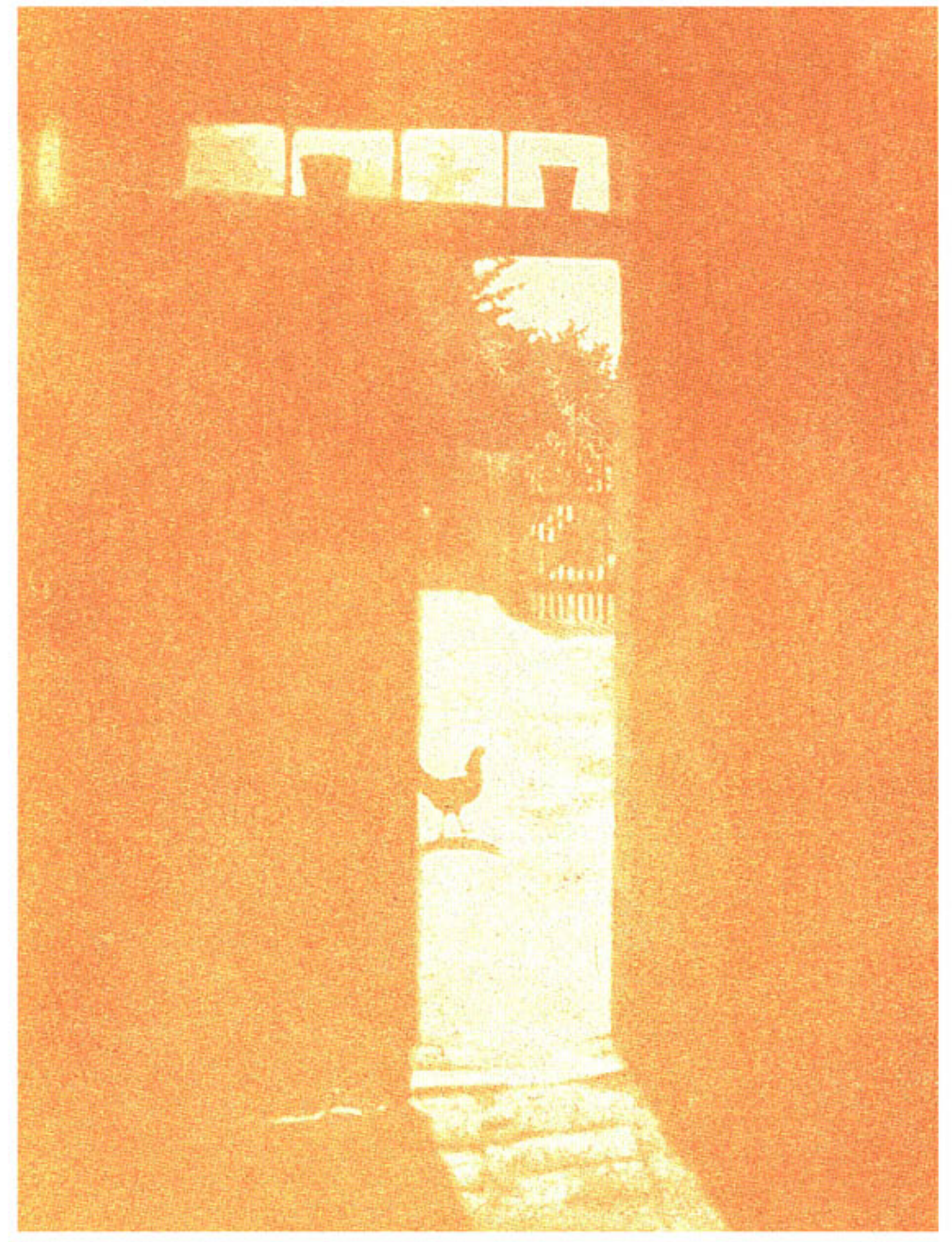




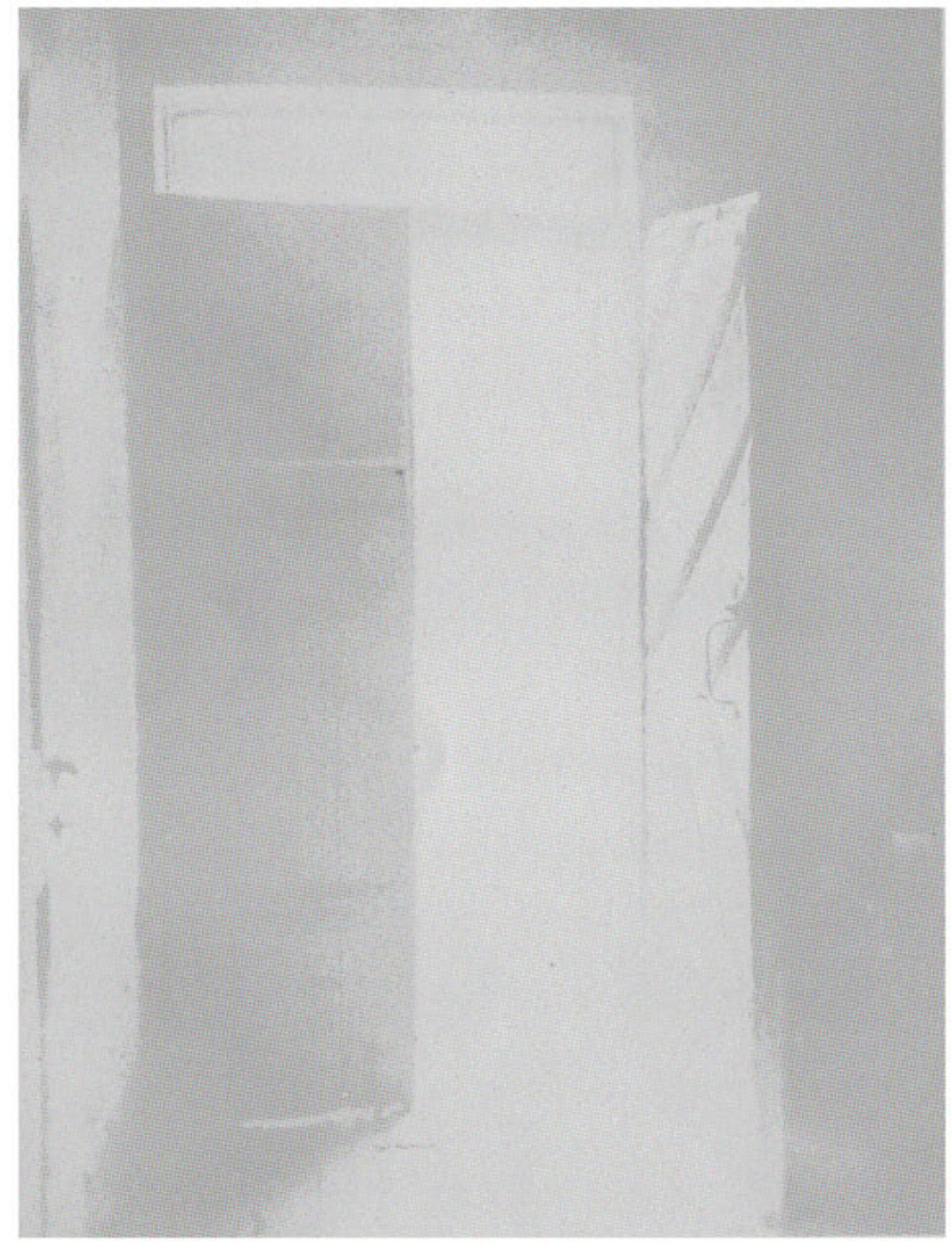

